\title{
A política do pensamento
}

\author{
Virgínia de Araújo \\ Figueiredo ${ }^{l}$
}

Para ser fiel, deve-se contar tudo, mesmo correndo o risco de ir de encontro à regra do "estilo filosófico" que nos obriga a deixar de lado como escória todo aspecto chamado "biográfico". Mas existem articulações, disso estou certa hoje, que não chegamos a esclarecer inteiramente a não ser com a ajuda dessa escória biográfica. Inicio esta homenagem a Philippe Lacoue-Labarthe contando uma breve história cujo sentido, espero, não esteja reduzido ao anedótico.

Vi Philippe pela primeira vez em outubro de 1989. Ele residia ainda na rua Charles Grad. Eu acabara de chegar a Strasbourg para estudar com ele. Eu tinha um projeto sobre a estética de Kant. Ele ficou um pouco surpreso, talvez porque eu estivesse grávida; talvez por causa da distância do meu país, o Brasil. Ele então me perguntou por que eu havia vindo de tão longe para estudar em Strasbourg. Depois de lhe contar um pouco das minhas dificuldades para realizar estudos de estética no Brasil, ele me respondeu com seu humor incomparável: "Imagino. A filosofia analítica domina todos os departamentos de filosofia do mundo, exceto em Strasbourg, onde nós tomamos o poder!" Saí desse primeiro encontro totalmente tranqüilizada. "Sim!", disse para mim mesma, "eles tomaram o poder, $\mathrm{E}$ eu, tomei a decisão certa quando vim aqui."

Eu não podia imaginar o quanto este primeiro encontro seria revelador do engajamento político de Philippe com a filosofia. Vendo a coisa retrospectivamente, eu me digo: é claro, eu devia ter percebido, uma vez que era justamente a sua maneira política de ler Heidegger que me fascinara sempre, desde a primeira vez que entrei em contato com seus textos. Foi em 1986. Eu estava redigindo minha dissertação de mestrado a respeito da filosofia heideggeriana sobre a arte e tinha me casado com um psicanalista lacaniano que havia lido $L e$ titre de la lettre e me prevenido sobre a ligação entre o pensamento de Lacoue-

1 Tradução: Sérgio Medeiros 
Labarthe e o de Heidegger. Fato raro nessa época no Brasil, eu havia conseguido comprar seu livro L'imitation des modernes no mesmo ano de seu lançamento na França. Eu o encontrei por acaso numa livraria do centro do Rio de Janeiro que importava livros, sobretudo franceses. Entrei ali sem expectativa definida. E saí com a intuição de que havia adquirido um dos livros mais importantes para a minha formação. Não estava errada. Depois que li seus ensaios sobre Hölderlin e Heidegger, não consegui mais me separar deles. Eu os li e reli várias vezes. Alguns anos mais tarde, no volume La fiction du politique, encontrei definitivamente aquilo de que eu mais sentia falta, no Brasil - ou em certo heideggerianismo brasileiro --: uma reflexão política sobre o pensamento de Heidegger.

0 que mais me faltava (essa "explication avec Heidegger") foi resumido por Lacoue-Labarthe na Advertência a La fiction du politique:

Ce qui devait se présenter, peu ou prou, comme une 'explication avec moi-même' a pris l'allure, sans doute osée (ou prétentieuse), d'un 'explication avec Heidegger'. La raison en est très simples: je ne suis 'entré en pbilosopbie', si j'y suis entré, que pour avoir subi le coup ou le choc (Stoss, est-til dans 'L'Origine de l'oeuvre d'art') de la pensée de Heidegger. Presque au même moment - il s'en est fallu de quelques mois - j'ai appris que Heidegger avait adbéré au nazisme. Et je dois avouer que, comme beaucoup d'autres, je ne m'en suis jamais remis. Si l'on aime mieux: quelle que soit l'admiration qui fut (et reste) la mienne à l'égard de la pensée de Heidegger, de cette adhésion je ne peux, et je n'ai jamais pu, politiquement et plus que politiquement, m'accommoder. ${ }^{3}$

Sim, diante da equação que uniu Heidegger e o nazismo, a questão do Ser e Auschwitz, o sentimento de repulsa é inevitável. Gostaríamos verdadeiramente que esta equação jamais pudesse ter sido formulada, que a adesão de Heidegger ao nazismo jamais tivesse acontecido. Talvez porque tenhamos alguma preguiça para pensar e a guinada política (ele o disse na Poétique et Politique) de Heidegger nos faça pensar muito. Diante desse acontecimento dolorosamente irreversível, três posiçōes pelo menos são possíveis. Ainda que haja sempre um pouco de incorreção nas "classificações", faço apelo às que nos foram propostas por Catherine David, a fim de tentar introduzir as posições filosófico-políticas também assumidas pelo heideggerianismo no Brasil. Isso me permitirá talvez falar um pouco sobre a recepção (se houve uma) do pensamento de Lacoue-Labarthe no Brasil, sobretudo no que se refere à sua contribuição insuperável sobre "O caso Heidegger", a respeito da qual, tanto quanto sei, o nosso ambiente filosó. fico continua a resistir. Infelizmente.

Tal como na França, no Brasil a atitude mais comum consiste também na recusa em reconhecer a importância do pensamento de Heidegger, considerando-o simplesmente como um nazista, ou um impostor. Se examinarmos ainda que de maneira muito superficial a "política" das editoras brasileiras, poderemos constatar isto:

2 IACOUE-LABARTHE, Ph. La fiction du politique, Paris: Christin Bourgois Ed., 1987, pp. 11-12.

3 DAVID, Catherine, "Lintroduction" ao "Dossier: Heidegger et la pensée nazie", Le Nouvel Observateur, Janeiro, 1988. 
que a "facção" anti-heideggeriana (e mesmo os que ostentam uma falta de respeito total pelo pensamento do filósofo alemão) conheceu um avanço desproporcional em relação à outra "facção", a dos que levam a sério o pensamento de Heidegger. Isso pode ser comprovado, por exemplo, pela recepção de um livro como o de Victor Farias, que teve grande sucesso no final dos anos 1980, não apenas na França, mas também no Brasil , onde foi logo traduzido, se não estou enganada, no ano seguinte à sua publicação na França. Um outro exemplo, ainda mais expressivo, é o livro de Jean-Pierre Faye, La raison narrative, sobre a filosofia heideggeriana. Publicado na França em 1990, portanto dois anos depois de La fiction du politique (que, passadas duas décadas, continua sem tradução em português), foi traduzido no Brasil em 1996, e seu autor, convidado a fazer uma conferência na Universidade Federal do Rio de Janeiro. Não li seu livro, mas (ou por que) fui ouvir sua conferência, que ele concluiu com a afirmação de que o principal interlocutor de Heidegger era Ernest Krieck, o reitor da Universidade de Frankfurt, eleito no mesmo ano (1933) que Heidegger... Segundo ele, os interlocutores de Heidegger não eram Nietzsche, Hegel ou Kant, não havia portanto "diálogo entre pensadores", como Heidegger definiu um dia a filosofia, mas "diálogo entre reitores"... Não! Paro aqui, pois não é minha intenção apresentar toda a série de mal-entendidos sobre "o caso Heidegger". Para finalizar esta primeira atitude, lembrarei o anexo (sobre o livro de Victor Farias) de Fiction du politique, onde escreve Lacoue-Labarthe:

S'il y a un 'cas Heidegger', qui ne s'est illustré - que je sache - par aucun 'crime contre l'bumanité', même si sa silencieuse complicité est terrifiant, c'est parce qu'il a la 'pensée de Heidegger'. La compromission politique n'est pas celle de tel ou tel, professeur ici ou là, adbérent No. tant du Parti, sinon on n'y consacrerait pas cinq minutes; c'est celle du plus grand penseur de ce temps. C'est dans sa pensée que se pose donc la question de sa responsabilité politique. ${ }^{4}$

A segunda posição, favorável ao pensamento de Heidegger, tende a rechaçar o episódio político como uma falta, reconhecidamente lamentável, mas sem conseqüências para o seu pensamento. Do lado francês, Catherine David havia incluído François Fédier. Do nosso lado brasileiro, com raras exceções, diria que essa posição é majoritária. Porém, na minha opinião, nessa posição, muito condescendente, eu colocaria ninguém menos do que Hannah Arendt. No seu belíssimo "Martin Heidegger at eighty" ", ela sustenta que uma inocência quase infantil caracterizaria não apenas a atitude de Heidegger, mas a de todos os grandes filósofos. $\mathrm{O}$ argumento principal do texto é conhecido. Trata-se de uma certa concepção do pensamento como imaginação. Ela retoma a lenda que Platão havia narrado no Teeteto (173d-176) sobre o sábio Tales e a moça da Trácia: " Foi o caso de Tales, Teodoro, quando observava os astros; porque olhava para o céu, caiu num poço. Contam que uma decidida e espirituosa rapariga da Trácia zombou dele, com dizer-lhe que ele procurava conhecer o que se passava no céu mas não via o que estava junto dos próprios pés. Essa pilhéria se aplica a todos os que

4 LACOUE-LABARTHE, Ph. Op. cit., p. 187.

5 ARENDT, H. "Martin Heidegger at eighty" in Heidegger and modern pbilosophy, ed. Michael Murray, New Haven, Vale University Press, 1978. 
vivem para a Filosofia". ${ }^{6}$

Comparando a adesão de Heidegger ao nazismo à adesão de Platão a Siracusa, Arendt escreve:

We who wish to bonor the thinkers, even if our oun residence lies in the midst of the world, can bardly belp finding it striking and perbaps exasperating that Plato and Heidegger, when they entered into buman affairs, turned to tyrants and Fübrers. This should be imputed not just to the circumstances of the times and even less to preformed character, but rather to what the French call a déformation professionelle.

Entre os argumentos mais importantes que Arendt reuniu nesse ensaio em homenagem a Heidegger, vou destacar pelo menos dois: inicialmente, a já mencionada definição do pensamento como imaginação, como um ato que nos afasta do continuum dos nossos negócios; em segundo lugar, a essência "ficcionante" (fictionante) da razão. A consequiência inevitável do exercício da imaginação seria a de distanciar os homens do mundo comum. Ao opor a filosofia à política, Arendt acabou por justificar a tendência que têm os filósofos (os homens de imaginação?) de sucumbirem à atração pelos tiranos e Führers. A conclusão se aproxima perigosamente da banalidade: os filósofos estão no mundo da lua. Se posso compreender a grande generosidade da leitura de Arendt, parece-me difícil, por outro lado, entender os motivos que poderiam justificar a resistência do heideggerianismo brasileiro a enfrentar o problema.

Reconheço que a terceira posição - a única a encarar verdadeiramente a questão "Heidegger e o nazismo" - é, sem dúvida, muito mais difícil. É aqui que encontro Philippe Lacoue-Labarthe. Este não busca "nem conciliar nem negar esses dois extremos, o irreconcliável e o inegável. Por um lado, Heidegger era um imenso pensador, e Sein und Zeit [Ser e Tempo] é um dos grandes livros da história da humanidade. Por outro lado, esse gênio imortal manteve ralaçōes com os assassinos mais deploráveis, mais inumanos. (...).Ele jamais se explicou verdadeiramente" 8

Ao contrário do filósofo da lenda contada no Teeteto, os olhos de Philippe não estão de maneira nenhuma voltados para o céu; atentos, voltam-se de maneira obstinada para o nosso mundo, para a nossa atualidade, que coloca a questão eminentemente filosófica do bic et nunc, voltam-se para a questão "quem somos?". Mesmo balbuciando uma resposta poética, provisória, na sua voz baixa e grave, ele jamais abandonou o lugar do político. Ao contrário de Heidegger, ele não se refugiou, ele nunca se furtou a explicar-se, a uma "explication avec", a uma "Auseinandersetzung". De acordo com Arendt, existe uma relação intrínseca entre essa palavra e a essência do político. Heidegger se serviu dela para traduzir a vocábulo grego "polemos", no fragmento 53 de Heráclito. Arendt nos oferece a sua própria versão da Auseinandersetzung como tradução do termo grego "logon didonai". Ela escreve nas Lectures on Kant's Political Pbilosophy:

\footnotetext{
PLATÃo. Diálogos: Teeteto/Crátilo, trad. de Carlos Alberto Nunes, Belém: EDUFPA, 2001, p.83.

ARENDT, H. Op. Cit., p. 303.

DAVID, Catherine. "Heidegger et la pensée nazie", p. 42.
} 


\section{Itha de Santa Catarina}

The term itself is political in origin: to render accounts is what Athenian citizens asked of their politicians, not only in money matters but in matters of politics. They could be beld responsible. And this - bolding oneself and everyone else responsible and answerable for what be thought and taught - was what transformed into philosophy that searcb for knowledge and trutb that bad sprung up in Ionia. ${ }^{9}$

Para ela, o termo "logon didonai" tem tal importância que seria a linha divisória entre Platão e seus predecessores:

[Plato] saw the difference between bimself and the 'wise man' of old, the Presocratics, in the fact that they, wise though they were, never gave an account of their thoughts. There they were, with their great insigbts; but when you asked them a question, they remained silent. Logon didomai, 'to give an account' - not to prove, but to be able to say bow one came to an opinion and for what reasons and formed it - is actually what separates Plato from all of his predecessors. ${ }^{10}$

Tentando compreender nossa (brasileira) resistência a encarar o problema "Heidegger e o nazismo", indagando o quanto este poderia nos revelar da essência da política moderna que permanece no escuro, dirijo-me agora a ti, Philippe, porque não devias ter partido antes de nos haver ensinado tua coragem, que é a virtude política por excelência; sem haver nos ensinado teu rigor, a virtude filosófica por excelência; teu silêncio, a virtude poética por excelência; tua generosidade, a virtude crítica por excelência; sem nos haver preparado para receber tão importante legado: o de se expor, sem trégua e da maneira mais rigorosa, ao trágico de nossa condição contemporânea. Não, tu partiste muito cedo. Não estávamos prontos para te perder.

9 ARENDT, Hanna. Lectures on Kant's Political Pbilosophy, edited and with an interpretive essay by Ronald Beiner, Chicago: The University Chicago Press, 1982,. P. 41.

10 ARENDT, H. Idem, p. 41. 